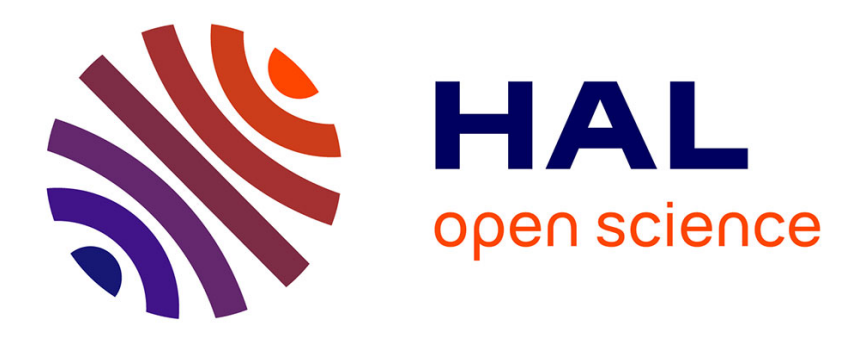

\title{
Low-Level Radiofrequency Exposure Induces Vasoconstriction in Rats
}

Thi Cuc Mai, Anne Braun, Véronique Bach, Amandine Pelletier, René de Seze

\section{To cite this version:}

Thi Cuc Mai, Anne Braun, Véronique Bach, Amandine Pelletier, René de Seze. Low-Level Radiofrequency Exposure Induces Vasoconstriction in Rats. Bioelectromagnetics, 2021, 10.1002/bem.22350 . ineris-03246969

\section{HAL Id: ineris-03246969 \\ https://hal-ineris.archives-ouvertes.fr/ineris-03246969}

Submitted on 30 Jun 2021

HAL is a multi-disciplinary open access archive for the deposit and dissemination of scientific research documents, whether they are published or not. The documents may come from teaching and research institutions in France or abroad, or from public or private research centers.
L'archive ouverte pluridisciplinaire HAL, est destinée au dépôt et à la diffusion de documents scientifiques de niveau recherche, publiés ou non, émanant des établissements d'enseignement et de recherche français ou étrangers, des laboratoires publics ou privés. 


\section{Low-level radiofrequency exposure induces vasoconstriction in rats}

Thi Cuc Mai ${ }^{1,2 *}$, Anne Braun ${ }^{1,2}$, Veronique Bach ${ }^{1,2}$, Amandine Pelletier $^{1,2, \#}$, and Rene de Seze ${ }^{1,2, \#}$

${ }^{1}$ Experimental Toxicology Unit, National Institute of Industrial Environment and Risks (INERIS), Parc technologique Alata, Verneuil-en-Halatte, France

2PeriTox Laboratory, UMR-I 01 INERIS, Picardie Jules Verne University, Amiens, France

\# These authors contributed equally to this work

* Corresponding author

Thi Cuc Mai

Experimental Toxicology Unit and UMR I-01 PeriTox, National Institute of Industrial Environment and Risks (INERIS), Parc technologique Alata, Verneuil-en-Halatte, France

Email:maicuc1610@gmail.com

Tel: +33611324063

Grant sponsor: INERIS, under the Program 190 funded by the Ministry in charge of Environment

Running title: Radiofrequency induces vasoconstriction

Conflict of interest: none 


\section{Abstract}

Recent studies have revealed that rodents' physiological responses to low intensity radiofrequency electromagnetic fields $(\mathrm{RF})$ were similar to thermoregulatory responses to cold conditions. The primary autonomic response to cold exposure is peripheral vasoconstriction that allows rodents to reduce heat loss and maintain a relatively constant internal body temperature. In the present study, we investigated the effects of $900 \mathrm{MHz}$ RF at a low level (SAR of $\left.0.35 \mathrm{~W} . \mathrm{kg}^{-1}\right)$ on tail skin temperature $\left(T_{\text {tail }}\right)$ in rats. We showed that rats exposed to $R F$ had lower $\mathrm{T}_{\text {tail }}$ than control rats at ambient temperatures between 27 and $28{ }^{\circ} \mathrm{C}$, suggesting that RF could induce a noticeable degree of vasoconstriction under mild-warm ambient temperatures. This difference in $T_{\text {tail }}$ was suppressed after the intraperitoneal injection of a vasodilator, an $\alpha$-adrenergic antagonist, confirming the hypothesis of the vasoconstriction in exposed rats. Moreover, like a response to cold stimuli, RF exposure led to a higher plasma concentration of important factors involved in response to cold: noradrenaline, a neurotransmitter responsible for vasoconstriction and thermogenesis, and fatty acids, markers of activated thermogenesis. Taken together, these findings indicate that low-intensity RF levels triggered some key physiological events usually associated with responses to cold in rats.

Keywords: radiofrequency; ambient temperature; tail skin temperature; vasoconstriction; thermogenesis 


\section{Introduction}

Thermal effect is the main effect of radiofrequency (RF) electromagnetic field exposure and is observed as a result of the absorption of RF energy in biological materials. The rate of RF energy absorption per unit mass of biological tissue is defined as the specific absorption rate (SAR), and an SAR value of $4 \mathrm{~W} \cdot \mathrm{kg}^{-1}$ is considered the threshold for a health risk from RF. Indeed, this SAR level decreases work performance and induces heating by 0.5 to $1{ }^{\circ} \mathrm{C}$ [D'Andrea et al., 2007; ICNIRP, 2020]; therefore, it is often called the thermal threshold. Recent studies have revealed significant effects of low-intensity RF (below the thermal threshold) on the thermoregulatory system in rodents, paradoxically mimicking a physiological response to hypothermia instead of the usual known response to hyperthermia at higher RF levels. Indeed, Pelletier et al. [2013] demonstrated that rats exposed to $900 \mathrm{MHz}$ RF with an intensity of 10 $\mathrm{mW} \cdot \mathrm{kg}^{-1}$ had lower tail temperature than controls at an ambient temperature of $31^{\circ} \mathrm{C}$ and showed that this was due to peripheral vasoconstriction. Also, the significantly preferred environmental temperature of RF-exposed rats was higher than that of control rats: whereas controls spent more time asleep at $28^{\circ} \mathrm{C}$, exposed rats spent more time at $31^{\circ} \mathrm{C}$ [Pelletier et al., 2014], which corresponded to a warm-seeking behavior. A similar effect was also observed by Arendash et al. [2012] where repeated RF exposure (twice 1h/day for 1 week at $918 \mathrm{MHz}$, 0.25-1.05 W. $\mathrm{kg}^{-1}$ ) induced a body temperature rise of $1{ }^{\circ} \mathrm{C}$ in mice during the exposure that did not occur in the first days. Since this temperature increase did not occur on the first exposure days, this effect should not be interpreted as a thermal load from RF exposure. Instead, it may correspond to non-shivering thermogenesis, which is a heat production mechanism in adipose tissues that contributes to mammals' thermoregulation during cold exposure. With the same exposure pattern to $900 \mathrm{MHz}$ RF with an SAR of $0.16 \mathrm{~W} \cdot \mathrm{kg}^{-1}$, we could confirm that after 4 days, body temperature in mice was shown to increase synchronously with RF exposure sessions, which also did not occur on the first days [Mai et al., 2020]. In these studies, the rodents' responses to RF were similar to those described for thermoregulation in cold conditions. These observations cannot be explained by the classical dielectric absorption mechanism underlying the thermal effects of RF. 
Upon exposure to cold, peripheral vasoconstriction is the primary autonomic response in rodents that allows them to reduce heat loss and maintain a relatively constant internal body temperature. Peripheral vasoconstriction occurs in both non-hairy (palms, souls of feet, lips, tip of nose, and ears) and hairy skin (rest of the body) of animals [Tansey and Johnson, 2015]. In rats, the tail is the primary site of heat transfer to the environment due to its extensive network of blood vessels and sympathetic nerves [Smith et al., 1998]. Mechanistically, coldinduced vasoconstriction appears largely driven by sympathetic activity in which noradrenaline released from sympathetic nerves binds to $\alpha$-adrenergic $(A R)$ receptors and triggers vascular smooth muscle contraction in the rat tail to reduce the level of heat exchange with the environment [Johnson et al., 2011; McCorry, 2007; Veicsteinas et al., 1982]. Thus, understanding the critical role of the tail in rodents' thermoregulation, previous studies have investigated the effects of low-level RF on this effector organ. After 5 weeks of $900 \mathrm{MHz} R \mathrm{FF}$ exposure, at an ambient temperature of $31^{\circ} \mathrm{C}$, the tail temperature of exposed animals was $1.2{ }^{\circ} \mathrm{C}$ lower than that of controls [Pelletier et al., 2013]. One hypothesis could be that, in response to RF, the threshold ambient temperature for triggering vasodilation could be shifted towards higher temperatures in exposed animals so that vasoconstriction would be maintained at $31{ }^{\circ} \mathrm{C}$ in exposed rats. In this study, to further understand the effect of RF and ambient temperature on vasomotor responses, we measured changes in tail temperature of rats exposed to $900 \mathrm{MHz} \mathrm{RF}$ at an SAR of $0.35 \mathrm{~W}^{\mathrm{kg}} \mathrm{kg}^{-1}$ in a range of increasing ambient temperatures from 24 to $34{ }^{\circ} \mathrm{C}$. Then, we evaluated the implication of $\alpha$-AR receptors by using a vasodilator (prazosin).

To further confirm the activation of cold responses under RF exposure, we evaluated the RF involvement in thermogenesis. Thermogenesis is activated by the sympathetic tone in cold environments, in which adipose tissue is the main tissue involved in this process in rodents. In this thermoregulatory response, the neurotransmitter noradrenaline stimulates $\beta_{3}$-adrenergic (AR) receptors of brown adipose tissues (BAT) and white adipose tissues (WAT), inducing lipolysis and releasing free fatty acids (NEFA) into blood circulation. NEFA then serve both as a source of energy for the thermogenesis process in these adipose tissues and as a substrate 
for fibroblast growth factor 21 (FGF21) synthesis in the liver. In turn, FGF21 delivered from the liver (the predominant source) or FGF21 produced directly by BAT and WAT can enhance the expression of many genes associated with the function of BAT and WAT thermogenesis [Bal et al., 2017; Cuevas-Ramos et al., 2019; Kim and Lee, 2014; Virtanen, 2014]. According to mechanisms of BAT and WAT thermogenesis, an increase in circulating noradrenaline enhances NEFA and FGF21 expressions. Therefore, to evaluate the effects of RF on thermogenesis responses and the implication of the sympathetic nervous system in our study, we assessed the concentration of noradrenaline, NEFA, and FGF21.

\section{Materials and Methods}

\section{Ethical considerations}

All animal procedures were approved by the nationally accredited Regional Ethical Committee (CREMEAP $\mathrm{n}^{\circ}$ 96) and the French Ministry of Research with the permit number 15889. All procedures involving the use of animals were performed in accordance with the European Directive 2010/63/EU and French governmental decree 2013-118, and annexes on the care and use of laboratory animals. From previous experiments in rats, it has been calculated that results on some key parameters of physiological response were clear enough to be achieved with groups of 4 animals rather than 6 or more. Then, according to the $3 R$ 's rules, it was decided to use, at the start, 4 animals per group in this study.

\section{Exposure system and dosimetry}

Whole-body exposure to $900 \mathrm{MHz} \mathrm{RF}$ was performed in two reverberation chambers built by IT'IS Foundation (Zurich, Switzerland) [Capstick et al., 2017] (Fig. S1). In this system, the signals are generated using an SMIQ02B signal generator (Rohde and Schwarz, Munich, Germany) and power is provided through $700 \mathrm{MHz}-2.2 \mathrm{GHz}$ amplifiers (TE UMS 015 AA, IT'IS Foundation, Zurich, Switzerland). Each chamber has two stirrers (vertical and horizontal) and three log-periodic broadband antennas, $700 \mathrm{MHz}-2.2 \mathrm{GHz}$ custom (SPEAG, IT'IS Foundation, Zurich, Switzerland), to excite the reverberant cavity. The antennas are each directed at one of the stirrers to ensure the best field homogeneity. The electric field in the chamber is monitored by using two ER3DV5 E-field probes (SPEAG, IT'IS Foundation, Zurich, 
Switzerland). Each chamber is also equipped with lighting, ventilation, and air temperature control.

The dosimetry for rats at $900 \mathrm{MHz}$ RF in these reverberation chambers was performed by the IT'IS Foundation. The dosimetry assessment was carried out using the the finite difference time domain (FDTD) method, as previously described [Gong et al., 2017]. Experimental dosimetry was also performed along with the numerical dosimetry in these reverberation chambers. The physical phantom was made from a half liter bottle, $552 \mathrm{ml}$, with tissue simulating liquid HSL900 $\left(\varepsilon_{r}=41.5\right.$ and $\sigma=0.97$ S.m $\left.{ }^{-1}\right)$. The SAR was determined experimentally by placing 20 phantoms in individual cages inside the reverberation chambers and exposing them at a high intensity $\left(305 \mathrm{~V} \cdot \mathrm{m}^{-1}\right)$ to produce a significant temperature rise. The SAR was determined to be $4.4 \mathrm{~W} \cdot \mathrm{kg}^{-1}$ at $305 \mathrm{~V} \cdot \mathrm{m}^{-1}$ from the heating and cooling curves of the phantoms.

In this experimental design, one chamber was used for real exposure with a continuous RF signal at $900 \mathrm{MHz}, 0.35 \mathrm{~W} \cdot \mathrm{kg}^{-1}, 23 \mathrm{~h}$ per day. The other chamber was used as a sham, under similar conditions but without radiation exposure.

\section{Animal housing}

Three week-old male Wistar rats were purchased from Janvier Labs (Le Genest Saint Isle, France). The rats were acclimated to their environment for 5 days following their arrival in the animal facility. During this acclimatization period, they were housed two per polycarbonate cage. Environmental conditions were controlled: $12 \mathrm{~h}$ dark-12 h light cycle, lights on at 7:00 am and off at 7:00 pm, the ambient temperature of $22 \pm 2{ }^{\circ} \mathrm{C}$, relative air humidity of $55 \pm 15 \%$. Food and filtered tap water were available ad libitum.

After the acclimatization period, the rats were shifted to the reverberation chambers to conduct the experiment. They were still housed in groups of two per cage, except during temperature monitoring, where they were housed individually to facilitate the measurement of tail temperature. To avoid inhomogeneity in RF exposure due to metallic components, rats' cages were covered with plastic grids (50\% linear apertures for air exchange). Food was contained in ceramic bowls and filtered tap water was contained in water bottles with plastic nipples. 
During temperature monitoring, the cage lids were removed to allow temperature recording, as infrared radiations are blocked by plastic. The lid was therefore replaced by a system of plastic walls fitted on the cage that was high enough to prevent escape.

\section{Experimental design}

The rats were randomized into 2 groups, exposed (EXPO) and control (SHAM) groups $(n=4)$. The EXPO group was exposed to a continuous RF signal at $900 \mathrm{MHz}, 0.35 \mathrm{~W} \cdot \mathrm{kg}^{-1}$ for 6 consecutive days, $23 \mathrm{~h}$ per day (one-hour period reserved for rat care from 9:00 am to 10:00 am). The SHAM group was placed in the chamber without exposure to RF field signals. Rats of both groups were housed at the ambient temperature (Ta) of $24{ }^{\circ} \mathrm{C}$ during the first 6 days. On the seventh day of the experiment, starting at 10:00 am, Ta of the chambers was set to rise from 24 to $34^{\circ} \mathrm{C}$, by steps of $1^{\circ} \mathrm{C}$ every $30 \mathrm{~min}$. The temperature was found to equilibrate at the new value in the chambers in less than 5 min. Tail skin temperature was recorded by an infrared camera (Fig. S2). Thereafter on the same day, Ta of the chambers was reset at $24{ }^{\circ} \mathrm{C}$ and both groups were followed up for two more days.

On the tenth day of the experiment, 30 min prior to the onset of RF exposure, a vasodilatoralpha adrenergic antagonist, prazosin (P7791, Sigma Aldrich, St Louis, MO), was injected intra-peritoneally at a dose of $1 \mathrm{mg}^{-1} \mathrm{~kg}^{-1}$ in both groups. The drug was first dissolved in polyethylene glycol followed by dilution with saline [Silvani et al., 2014]. After prazosin injection, tail skin temperature was recorded during $6 \mathrm{~h}$ from $10: 00$ to $16: 00$ at Ta of $27^{\circ} \mathrm{C}$.

At the end of the experiment, the rats were euthanized by an intraperitoneal injection of a lethal dose of sodium pentobarbital (400 mg.ml-1 EXAGON, Richter Pharma, Wels, Austria). Blood samples were collected by cardiac puncture and adipose tissues were then rapidly removed and weighed.

\section{Tail skin temperature measurement}

On the seventh and tenth days of the experiment, an infrared thermocamera PI 640 with microscope optics (Optris, Berlin, Germany) was used to measure the tail skin temperature of rats. This method can accurately and rapidly measure the tail skin temperature based on the infrared radiation emitted from the skin surface. The camera has a precision of $2 \%$, a thermal 
sensitivity (NETD) of $75 \mathrm{mK}$, and a spatial resolution of $640 \times 480$ pixels. As there was only one IR camera available at the time of the experiment, the experiment could not be blinded. In the reverberation chamber where the temperature was measured, the camera was positioned on the top of the chamber, $95 \mathrm{~cm}$ above the rat cages (at this distance: 1 pixel = $0.9 \mathrm{~mm}$ ). The skin emissivity of the rat's tail was set to 0.97 . Infrared data were acquired and analyzed with image analysis software Optris PI (Messtechnik Schaffhausen, Berlin, Germany). The tail temperatures displayed in this study were the maximum temperature at the dorsal surface of the proximal part of the tail (over 20 pixels length from the root of the tail) and of the distal part of the tail (over 20 pixels length from the end of the tail). The addressed part of the tail was selected manually, and the detection of maximum temperature was programmed to be automatic.

On the seventh day, Ta was increased by $1{ }^{\circ} \mathrm{C}$ every $30 \mathrm{~min}$. Images of tail skins were taken at 5-min intervals. At each Ta, the tail skin temperature of each group was averaged from 4 rats (6 values in 30 min at a given Ta for each rat).

On the tenth day of the experiment, the tail skin temperatures were measured at 1-h intervals during $6 \mathrm{~h}$ after prazosin injection. At each measurement time, the average tail skin temperature of each group was calculated from 4 rats.

\section{Body and tissue masses, food and water intake}

Body masses of rats were monitored daily throughout the experiment (between 9:00 am and 10:00 am). White adipose tissue and brown adipose tissue masses were measured at the time of euthanasia. Total food and water intake for 10 days of the experiment were also calculated for each group. As rats were housed two per cage, consumption measurements were only indicative (no statistical analysis performed) and did not reflect individual quantities of food and water intake.

\section{Serum analysis}

Blood samples were collected in EDTA-treated tubes and plasma was prepared immediately by centrifugation (1000 rpm,10 min, $4{ }^{\circ} \mathrm{C}$ ). For all plasma analyses, commercially available assay kits were used according to the manufacturer's recommendations. Four samples per 
group were analyzed, all samples were run in duplicate wells, and no-template controls were included. The plasma concentrations of NEFA (Non-Esterified Fatty Acids) were measured using enzymatic colorimetric methods (NEFA C kit, Wako Chemicals, Neuss, Germany). Plasma noradrenaline and FGF21 concentrations were measured by ELISA methods: rat noradrenaline ELISA Kit (CSB-E07022r, Cusabio, Wuhan, China); mouse and rat FGF-21 ELISA kit (RD291108200R, BioVendor, Brno, Czech Republic).

\section{Statistical analysis}

Statistical analyses were performed using GraphPad Prism version 7.04 for Windows (GraphPad Software, San Diego, CA). The normality of the data was tested by the ShapiroWilk normality test. Data on tail skin temperature and body mass were analyzed by a two-way ANOVA with repeated measures followed by Bonferroni post-hoc test. The data of plasma noradrenaline, FGF21, NEFA concentrations, and fat masses were analyzed by Mann-Whitney $\cup$ Tests. Values are shown as means \pm SEM. The threshold for statistical significance was $p<0.05$. Post-hoc power analysis was calculated when results were not statistically significant.

\section{Results}

\section{Effect of RF exposure on body mass, fat mass, food and water intake}

Body masses of animals in both EXPO and SHAM groups were monitored daily over 10 days and results are presented in Figure S3a. The evolution of body mass in the EXPO group was not significantly different from the SHAM group. No significant difference in the mass of adipose tissues, both brown and white, was found between the 2 groups (Fig. S3b). The average mass of BAT was $0.64 \pm 0.05 \mathrm{~g}$ in the EXPO group and $0.50 \pm 0.02 \mathrm{~g}$ in the SHAM group $(p=0.1$; power=0.51). The average mass of WAT was $0.50 \pm 0.03 \mathrm{~g}$ in the EXPO group and $0.44 \pm$ $0.05 \mathrm{~g}$ in the SHAM group $(p=0.4 ;$ power=0.23). The total amount of food and water consumed by the EXPO group over 10 days was $18 \%$ and $17 \%$ higher than those of the SHAM group (data not shown). These measures of food and water consumption can only be considered as indicative, and more precise measurements will be performed in a future experiment.

\section{Effect of RF exposure on tail skin temperature}


Over the range of $\mathrm{Ta}$ between 24 and $34^{\circ} \mathrm{C}$, we found that the tail position of the rats changed, depending on Ta. Indeed, the rats in both groups often curled their tail around and close to their body on Ta ranging from 24 to $26{ }^{\circ} \mathrm{C}$, as a way of keeping the tail warm in a mildly cold environment. However, when Ta rose above $26{ }^{\circ} \mathrm{C}$, their tail was usually held away from the rest of the body, as shown in Figure S4. This natural behavior could provide an indicator of their thermic comfort. Tail skin temperature $\left(T_{\text {tail }}\right)$ was measured and averaged at each Ta (every $30 \mathrm{~min})$ and is presented for proximal ( $\left.T_{\text {tail-pro }}\right)$ and distal $\left(T_{\text {tail-dis }}\right)$ parts of the tail in Figure 1a.

On the proximal part of the tail, statistical analysis revealed a significant interaction between RF exposure and $\mathrm{Ta}\left(\mathrm{F}_{10,506}=2.53, \mathrm{p}=0.005\right)$. The increase of $\mathrm{Ta}$ up to $34^{\circ} \mathrm{C}$ led to a significant rise of $\mathrm{T}_{\text {tail-pro }}$ in both groups: $2.30{ }^{\circ} \mathrm{C}$ in the EXPO group and $2.41{ }^{\circ} \mathrm{C}$ in the SHAM group $\left(F_{10,506}=117.1, p<0.001\right)$. Over the range of Ta tested, statistically significant differences of the average $T_{\text {tail-pro }}$ were observed between the two groups at Ta of $27^{\circ} \mathrm{C}$ and $28^{\circ} \mathrm{C}$ where the $\mathrm{T}_{\text {tail- }}$ pro was $0.43^{\circ} \mathrm{C}$ less in the EXPO group compared to the SHAM group ( $p=0.01$ ) (Fig. 1a and Fig. S5). At Ta between 29 and $31^{\circ} \mathrm{C}$, the average $T_{\text {tail-pro }}$ of the EXPO group also tended to be lower than that of the SHAM group $\left(-0.33^{\circ} \mathrm{C}, \mathrm{p}=0.1\right.$ at $\mathrm{Ta} 29^{\circ} \mathrm{C} ;-0.35^{\circ} \mathrm{C}, \mathrm{p}=0.07$ at $\mathrm{Ta} 30$ ${ }^{\circ} \mathrm{C} ;-0.29{ }^{\circ} \mathrm{C}, \mathrm{p}=0.2$ at $\mathrm{Ta} 31{ }^{\circ} \mathrm{C}$ ), but the difference did not reach statistical significance. At Ta between 32 and $34^{\circ} \mathrm{C}, \mathrm{T}_{\text {tail-pro }}$ was similar between the EXPO and SHAM groups.

For the distal part of the tail, $T_{\text {tail }}$ appeared colder than that of the proximal part (from 1 to 2 $\left.{ }^{\circ} \mathrm{C}\right)$. With the increase of Ta, $\mathrm{T}_{\text {tail-dis }}$ increased respectively by $1.57^{\circ} \mathrm{C}$ in the EXPO group and $1.88{ }^{\circ} \mathrm{C}$ in the SHAM group $\left(\mathrm{F}_{10,506}=51.09, \mathrm{p}<0.001\right)$. However, there was no interaction between RF exposure and Ta on this part of the tail $\left(F_{10,506}=0.4, p=0.9\right)$.

To evaluate the Ta threshold at which vasodilation became most pronounced in both groups when increasing Ta from 27 to $31{ }^{\circ} \mathrm{C}$, the $\mathrm{T}_{\text {tail-pro }}$ over each 5-min interval of both groups was analyzed (Fig. 1b). At Ta below $30{ }^{\circ} \mathrm{C}, \mathrm{T}_{\text {tail-pro }}$ of both groups was kept almost stable, at an average of approximately $35.0^{\circ} \mathrm{C}$ in the SHAM group and $34.6{ }^{\circ} \mathrm{C}$ in the EXPO group. Then, a clear step-increase in $\mathrm{T}_{\text {tail-pro }}$ was seen for both groups at a Ta of approximately $30{ }^{\circ} \mathrm{C}$. 
Therefore, the Ta of $30{ }^{\circ} \mathrm{C}$ appeared to reflect the threshold Ta for an increase in tail blood flow by vasodilation, independently of RF exposure.

\section{Implication of $\alpha$-adrenergic receptors}

To investigate the implication of $\alpha$-adrenergic receptors in the RF effect on tail temperature, the a-adrenergic antagonist, prazosin, was injected in both groups on the tenth day of the experiment. Then, Ta of the two chambers was set at $27^{\circ} \mathrm{C}(\mathrm{Ta}$ at which the difference appeared in $T_{\text {tail-pro }}$ between the two groups, as mentioned above). $T_{\text {tail-pro }}$ was recorded at 1-h intervals for $6 \mathrm{~h}$ from 10:00 to 16:00 (Fig. 2).

After prazosin injection, at a $\mathrm{Ta}$ of $27^{\circ} \mathrm{C}$, a rise of $\mathrm{T}_{\text {tail-pro }}$ of approximately $1^{\circ} \mathrm{C}$ occurred in both groups in the first hour, then $\mathrm{T}_{\text {tail-pro }}$ returned to about $34{ }^{\circ} \mathrm{C}$ after $5-6 \mathrm{~h}$ of measurement, which may reflect an adaptation of rats to the environment. Throughout the $6-\mathrm{h}$ recording after prazosin injection, the average $T_{\text {tail-pro }}$ at each measurement time was no longer significantly different between the two groups, showing that effects of RF on $T_{\text {tail }}$ in EXPO group were inhibited by prazosin. This result indicated that the RF-induced decrease in tail temperature is likely to be mediated by vasoconstriction via $\alpha-A R$ receptors.

\section{Effect of RF exposure on thermogenesis.}

To further investigate the effect of RF exposure on thermogenesis, we measured plasma concentrations of Noradrenaline (NA), NEFA, and FGF21. Figure 3a shows that the NA concentration of the EXPO group was 3.5-fold higher compared to the SHAM group $(p=0.03)$. Moreover, the NEFA concentration in EXPO rats was 2-fold higher than in SHAM rats $(p=0.03)$ (Fig. 3b). Concerning plasma FGF21 (Fig. 3c), the concentration in EXPO group tended to be higher compared to SHAM group, but the difference did not reach statistical significance (247 \pm 45 pg.ml-1 vs $379 \pm 65$ pg. $\mathrm{ml}^{-1}, \mathrm{p}=0.1$; power $=0.40$ ).

\section{Discussion}

In the present study, we report the effect of $900 \mathrm{MHz}$ RF exposure at an SAR level of 0.35 W. $\mathrm{kg}^{-1}$ on rat tail temperature in conditions of ambient temperatures varying in a range from 24 to $34^{\circ} \mathrm{C}$. At ambient temperatures between 27 and $31^{\circ} \mathrm{C}$, RF-exposed rats had a lower tail temperature than control rats. In rats, the tail is the primary organ for heat exchange between 
the body and environment. The rate of heat exchange depends on blood flow in the tail skin, which is regulated by the autonomic nervous system via vasoconstriction or vasodilation. In thermoregulatory research, changes in vasomotor responses can be measured indirectly by monitoring changes in tail skin temperature, where an increase of tail temperature is an indication of an increase of blood flow, vasodilation, and vice versa [Key and Wigfield, 1994; Williams et al., 2010]. Thus, to evaluate these parameters in conditions of varying ambient temperature, we measured the rat's tail temperature by using the infrared camera. This approach, based on thermal imaging, is considered one of the most robust methods for providing accurate, continuous peripheral temperature values without contact or manipulation bias [Meyer et al., 2017].

First, we found that the rats often curled their tail at ambient temperatures under $26{ }^{\circ} \mathrm{C}$ and kept their tail away from their body at higher ambient temperatures. This natural behavior could serve as an indicator of the thermoneutral zone (TNZ) of rats in which the ambient temperature of $26{ }^{\circ} \mathrm{C}$ can be considered the lower limit of this range. This suggestion is consistent with previous studies where the rat's TNZ varies between 26 and $32{ }^{\circ} \mathrm{C}$ [Mallick and Kumar, 2012; Romanovsky et al., 2002]. Besides, this finding may indicate that values of tail temperature measured below an ambient temperature of $26{ }^{\circ} \mathrm{C}$ do not accurately reflect the tail's temperature.

Most importantly, we then found that RF-exposed rats, at a Ta ranging from 27 to $28{ }^{\circ} \mathrm{C}$, exhibited lower tail temperature compared to the SHAM group. This effect of RF on the tail temperature was observed specifically on the proximal part of the tail. There was no difference in tail temperature between the groups on the distal part. Not surprisingly, we found that temperature varies noticeably from the proximal to the distal part, the distal end being 1 to 2 ${ }^{\circ} \mathrm{C}$ cooler than the proximal part, for Ta ranging from 24 to $34{ }^{\circ} \mathrm{C}$. The lower $\mathrm{T}_{\text {tail-pro }}$ in exposed animals suggests that RF could maintain a noticeable degree of vasoconstriction under mildwarm ambient temperatures whereas vasodilatation should normally be activated, which supports earlier findings from the study of Pelletier et al. [2013]. As shown in our study, the $T_{\text {tail-pro }}$ difference between the EXPO group and SHAM group disappeared after injection of the 
vasodilator prazosin, confirming this observation. As prazosin acts primarily by blocking $\alpha_{1}-\mathrm{AR}$ receptors, this result indicates that RF could promote vasoconstriction via $\alpha_{1}$-AR receptors. The absence of RF effect on the distal part contrary to the proximal part could be explained by a higher expression of these $\alpha-A R$ types on the proximal part of the tail [Chotani et al., 2000]. However, in our experiment, the difference in $\mathrm{T}_{\text {tail-pro }}$ between the 2 groups was around $0.4{ }^{\circ} \mathrm{C}$, whereas a larger, $1.2^{\circ} \mathrm{C}$ difference, was found in Pelletier et al.'s study [Pelletier et al., 2013]. This could be explained by differences in rat age and RF exposure parameters, but it is likely mostly due to the exposure duration: the rats in our study were exposed to RF for one week only, instead of 6 weeks in Pelletier et al.'s study. Moreover, the RF parameters seem to play an important role since Wang et al. [2017] reported no difference in tail skin temperature of rats exposed to a single $1800 \mathrm{MHz}$ RF exposure for $30 \mathrm{~min}$ at an SAR of $3.3 \mathrm{~W} \cdot \mathrm{kg}^{-1}$. Thus, it seems plausible that RF-induced cold reactions such as vasoconstriction could only occur at much lower SAR values than the thermal threshold, and with repeated and/or chronic exposures.

The effect of low-intensity RF on tail temperature was also investigated by Alchalabi et al. [2015]. In apparent contradiction to our findings, they found an increase of rat tail temperature after 15- and 30-day exposure to $1800 \mathrm{MHz}$ RF at an SAR level of $0.048 \mathrm{~W} . \mathrm{kg}^{-1}$. However, their measurements, also by IR camera, were taken only after the exposure period. If the effect of RF causing vasoconstriction stops after the end of the exposure, a rebound phenomenon (vasodilation) could occur immediately thereafter, inducing an increase of tail temperature. Further experiments extending tail temperature measurements both during and after the exposure period will be needed to verify this hypothesis.

In this study, we also investigated three major factors implicated in the cold-induced thermogenesis process: NA, FGF21, and NEFA. In fact, thermogenesis in BAT and WAT has been well documented as an important response for cold defense. Similarly to the pathways for vasoconstriction, cold-stimulated thermogenesis is under the control of the sympathetic nervous system and the secretion of catecholamines, in particular, noradrenaline [LaVoy et 
al., 2011]. According to mechanisms of BAT and WAT thermogenesis, an increase in circulating NA enhances free fatty acid NEFA and FGF21 expression. It has been shown that plasma contains only a small amount of NA that derives from networks of sympathetic nerves enmeshed in blood vessels, because the main route of NA inactivation is by reuptake into the nerve terminals [Goldstein, 2010]. However, plasma NA concentration is used as an index of sympathetic neural activity [Goldstein et al., 1983; Macdonald and Siyamak, 1990], and it has been shown that NA in plasma is increased by cold [Din et al., 2018]. In our study, we observed a significant increase in plasma NA levels in exposed rats and, in agreement with this result, we found circulating NEFA were also significantly higher in exposed rats. Consistently, plasma FGF21 concentration also tended to be higher in exposed rats, but this difference did not reach statistical significance. This was possibly due to the small sample size, or it could also be explained by a local increase of FGF21 in adipose tissues, without a systemic increase in FGF21 circulation [Fisher and Maratos-Flier, 2016]. Taken together, these results showed that RF could activate the thermogenesis process, via activation of NA and NEFA production. To further establish the relationship between RF and thermogenesis, future studies will be needed to examine the effects of RF on key regulators of cold-mediated thermogenesis, in particular UCP1, PGC-1a, PPARy, and GLP-1a, and on the morphology and size of adipose tissues as well as their mitochondrial content [de-Lima-Júnior et al., 2019].

Although the small sample size, 4 rats per group, represents a limiting factor of this study, it was sufficient to show statistically significant differences in key parameters of the response to RF. Post-hoc power analysis was also calculated when results were not statistically significant to help guide the planning of future studies.

In conclusion, our data showed that low-intensity RF exposure induced vasoconstriction and could regulate key factors of thermogenesis, such as noradrenaline and fatty acid production. These responses resembled those described for thermoregulatory responses to cold. The tail temperature changes and other observed responses remained within a physiological amplitude, therefore without impairing rat health in our study. Although it is not possible to extrapolate whether these responses happen in other species including human, these findings 
should open the way for further in-depth studies on the effects of electromagnetic fields used in telecommunication technologies at low-intensity RF.

\section{References}

Alchalabi AS, Erkihun A, Abd Rahman A, Mohd AK. 2015. Thermal effect of chronic mobile phone radiation exposure at frequency $1800 \mathrm{MHz}$ on adult Sprague-Dawley rats. South Asian Journal of Experimental Biology 5:167-173.

Arendash GW, Mori T, Dorsey M, Gonzalez R, Tajiri N, Borlongan C. 2012. Electromagnetic treatment to old Alzheimer's mice reverses $\beta$-amyloid deposition, modifies cerebral blood flow, and provides selected cognitive benefit. PLoS One 7:e35751.

Bal NC, Singh S, Reis FC, Maurya SK, Pani S, Rowland LA, Periasamy M. 2017. Both brown adipose tissue and skeletal muscle thermogenesis processes are activated during mild to severe cold adaptation in mice. Journal of Biological Chemistry 292:16616-16625.

Capstick MH, Kuehn S, Berdinas-Torres V, Gong Y, Wilson PF, Ladbury JM, Koepke G, McCormick DL, Gauger J, Melnick RL. 2017. A radio frequency radiation exposure system for rodents based on reverberation chambers. IEEE Transactions on Electromagnetic Compatibility 59:1041-1052.

Chotani MA, Flavahan S, Mitra S, Daunt D, Flavahan NA. 2000. Silent a2C-adrenergic receptors enable cold-induced vasoconstriction in cutaneous arteries. American Journal of Physiology-Heart and Circulatory Physiology 278:H1075-H1083.

Cuevas-Ramos D, Mehta R, Aguilar-Salinas CA. 2019. Fibroblast growth factor 21 and browning of white adipose tissue. Frontiers in Physiology 10:e0127701.

D'Andrea JA, Ziriax JM, Adair ER. 2007. Radio frequency electromagnetic fields: mild hyperthermia and safety standards. Progress in Brain Research 162:107-135.

de-Lima-Júnior JC, Souza GF, Moura-Assis A, Gaspar RS, Gaspar JM, Rocha AL, Ferrucci DL, Lima TI, Victório SC, Bonfante IL. 2019. Abnormal brown adipose tissue mitochondrial structure and function in IL10 deficiency. EBioMedicine 39:436-447. 
Din MU, Saari T, Raiko J, Kudomi N, Maurer SF, Lahesmaa M, Fromme T, Amri E-Z, Klingenspor M, Solin O. 2018. Postprandial oxidative metabolism of human brown fat indicates thermogenesis. Cell Metabolism 28:207-216. e3.

Fisher FM, Maratos-Flier E. 2016. Understanding the physiology of FGF21. Annual Review of Physiology 78:223-241.

Goldstein DS. 2010. Catecholamines 101. Clinical Autonomic Research 20:331-352.

Goldstein DS, McCarty R, Polinsky RJ, Kopin IJ. 1983. Relationship between plasma norepinephrine and sympathetic neural activity. Hypertension 5:552-559.

Gong Y, Capstick MH, Kuehn S, Wilson PF, Ladbury JM, Koepke G, McCormick DL, Melnick RL, Kuster N. 2017. Life-time dosimetric assessment for mice and rats exposed in reverberation chambers for the two-year NTP cancer bioassay study on cell phone radiation. IEEE Transactions on Electromagnetic Compatibility 59:1798-1808.

ICNIRP. 2020. Guidelines for Limiting Exposure to Electromagnetic Fields (100 kHz to 300 GHz). Health Physics 118:483-524

Johnson JM, Minson CT, Kellogg Jr DL. 2011. Cutaneous vasodilator and vasoconstrictor mechanisms in temperature regulation. Comprehensive Physiology 4:33-89.

Key B, Wigfield C. 1994. The influence of the ventrolateral medulla on thermoregulatory circulations in the rat. Journal of the Autonomic Nervous System 48:79-89.

Kim KH, Lee M-S. 2014. FGF21 as a stress hormone: the roles of FGF21 in stress adaptation and the treatment of metabolic diseases. Diabetes \& Metabolism Journal 38:245-251.

LaVoy EC, McFarlin BK, Simpson RJ. 2011. Immune responses to exercising in a cold environment. Wilderness \& Environmental Medicine 22:343-351.

Macdonald I, Siyamak A. 1990. Plasma noradrenaline levels and thermogenic responses to injected noradrenaline in the conscious rat. Experimental Physiology 75:639-648.

Mai TC, Delanaud S, Bach V, Braun A, Pelletier A, de Seze R. 2020. Effect of non-thermal radiofrequency on body temperature in mice. Scientific Reports 10:1-9.

Mallick HN, Kumar VM. 2012. Basal forebrain thermoregulatory mechanism modulates autoregulated sleep. Frontiers in Neurology 3:102. 
McCorry LK. 2007. Physiology of the autonomic nervous system. American Journal of Pharmaceutical Education 71:78.

Meyer CW, Ootsuka Y, Romanovsky AA. 2017. Body temperature measurements for metabolic phenotyping in mice. Frontiers in Physiology 8:520.

Pelletier A, Delanaud S, de Seze R, Bach V, Libert J-P, Loos N. 2014. Does exposure to a radiofrequency electromagnetic field modify thermal preference in juvenile rats? PloS One 9:e99007.

Pelletier A, Delanaud S, Décima P, Thuroczy G, De Seze R, Cerri M, Bach V, Libert J-P, Loos N. 2013. Effects of chronic exposure to radiofrequency electromagnetic fields on energy balance in developing rats. Environmental Science and Pollution Research 20:2735-2746.

Romanovsky AA, Ivanov Al, Shimansky YP. 2002. Selected contribution: ambient temperature for experiments in rats: a new method for determining the zone of thermal neutrality. Journal of Applied Physiology 92:2667-2679.

Silvani A, Berteotti C, Bastianini S, Cohen G, Martire VL, Mazza R, Pagotto U, Quarta C, Zoccoli G. 2014. Cardiorespiratory anomalies in mice lacking CB1 cannabinoid receptors. PloS One 9:e100536.

Smith JE, Jansen AS, Gilbey MP, Loewy AD. 1998. CNS cell groups projecting to sympathetic outflow of tail artery: neural circuits involved in heat loss in the rat. Brain Research 786:153-164.

Tansey EA, Johnson CD. 2015. Recent advances in thermoregulation. Advances in Physiology Education 39:139-148.

Veicsteinas A, Ferretti G, Rennie DW. 1982. Superficial shell insulation in resting and exercising men in cold water. Journal of Applied Physiology 52:1557-1564.

Virtanen KA. 2014. BAT thermogenesis: linking shivering to exercise. Cell Metabolism 19:352354. 
Wang K, Lu J-M, Xing Z-H, Zhao Q-R, Hu L-Q, Xue L, Zhang J, Mei Y-A. 2017. Effect of 1.8 $\mathrm{GHz}$ radiofrequency electromagnetic radiation on novel object associative recognition memory in mice. Scientific Reports 7:44521.

Williams H, Dacks PA, Rance NE. 2010. An improved method for recording tail skin temperature in the rat reveals changes during the estrous cycle and effects of ovarian steroids. Endocrinology 151:5389-5394.

\section{Author contribution statements}

Thi Cuc Mai designed and performed the experiments, analyzed the data, and wrote the manuscript; Veronique Bach and Anne Braun corrected the manuscript and supervised the whole study; Amandine Pelletier and Rene de Seze originated the concept, designed experiments, revised the manuscript, and supervised the whole study.

\section{Figure Captions}

Figure 1. Tail skin temperature in the SHAM and EXPO groups. (a) Average tail skin temperature of the proximal ( $\left.T_{\text {tail-pro }}\right)$ and distal parts $\left(T_{\text {tail-dis }}\right)$ of the tail, at ambient temperatures ranging from 24 to $34{ }^{\circ} \mathrm{C}$. Each point represents the average from 4 rats \pm SEM (over $30 \mathrm{~min}$, 6 values per rat). (b) Tail skin temperature of the proximal part of the tail, every 5 min from 11:30 to $14: 00$ at ambient temperatures ranging from 27 to $31^{\circ} \mathrm{C}$. Each point represents the average from 4 rats. Data were analyzed by two-way ANOVA (effect of RF exposure and ambient temperature) with repeated measures followed by Bonferroni post-hoc test. Values are shown as means \pm SEM, ${ }^{*} p<0.05$.

Figure 2. Tail skin temperature after prazosin injection at ambient temperature of $27^{\circ} \mathrm{C}$. Each point is the average of 4 temperature values from 4 rats. Values are shown as means \pm SEM. Figure 3. Plasma concentrations of (a) NA, (b) NEFA, and (c) FGF21 in the SHAM and EXPO groups. Data were analyzed by Mann-Whitney U-tests. Values are shown as means \pm SEM, $n=4 .{ }^{*} p<0.05$. 
Figure S1. Exposure system.

Figure S2. Experimental setup during temperature monitoring. Rats were individually housed in plastic cages, 4 cages per reverberation chamber. Tail temperature was recorded by the IR camera.

Figure S3. (a). Body mass over time (10 days of the experiment). (b) Mass of brown adipose tissue (BAT) and white adipose tissue (WAT), at the end of the experiment, ns: not significant. Values are shown as means \pm SEM.

Figure S4. Position of the tail according to different ambient temperatures.

Figure S5. Tail skin temperature of the proximal parts of the tail at ambient temperatures ranging from 24 to $34{ }^{\circ} \mathrm{C}$. Each point represents one value of tail temperature. 
a

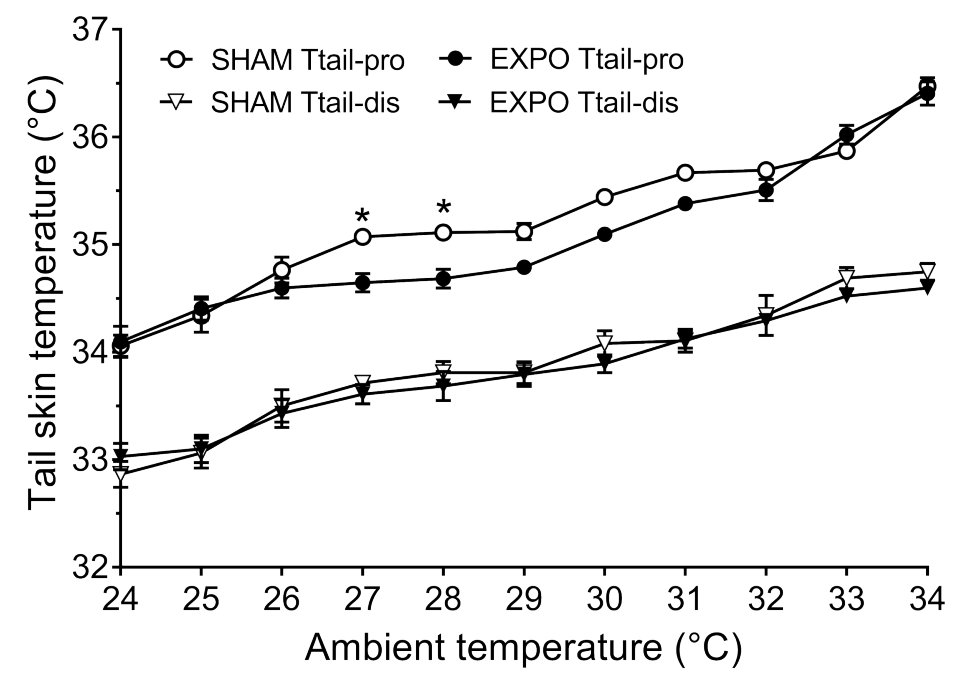

b

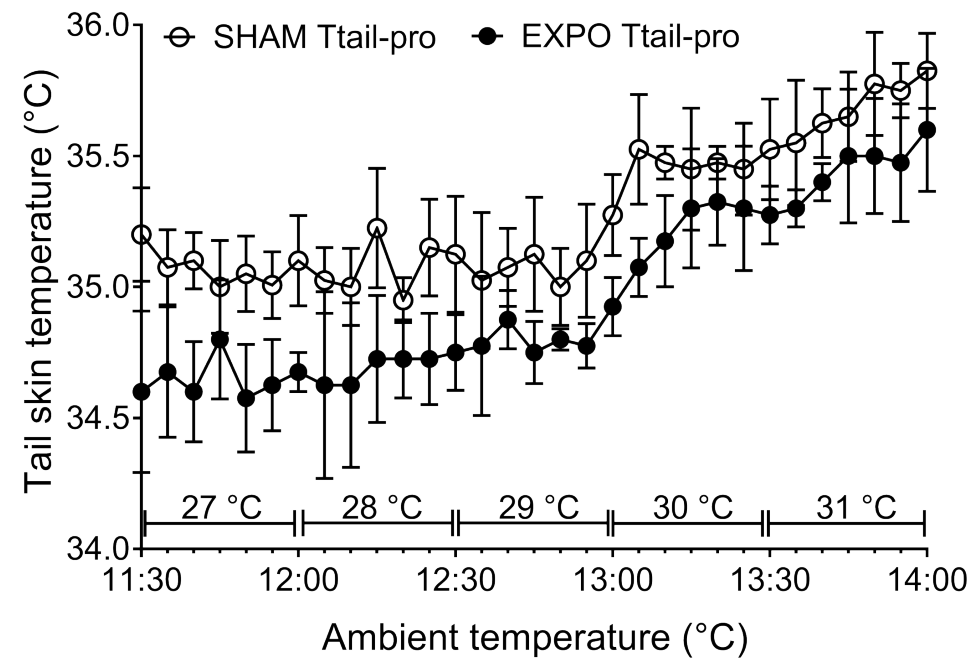

Figure 1. Tail skin temperature in the SHAM and EXPO groups. (a) Average tail skin temperature of the proximal ( $T_{\text {tail-pro }}$ ) and distal parts $\left(T_{\text {tail-dis }}\right)$ of the tail, at ambient temperatures ranging from 24 to $34{ }^{\circ} \mathrm{C}$. Each point represents the average from 4 rats $($ over 30 min, 6 values per rat). (b) Tail skin temperature of the proximal part of the tail, every 5 min from 11:30 to 14:00 at ambient temperatures ranging from 27 to $31{ }^{\circ} \mathrm{C}$. Each point represents the average from 4 rats. Data were analyzed by two-way ANOVA (effect of RF exposure and ambient temperature) with repeated measures followed by Bonferroni post-hoc test. Values are shown as means \pm SEM, ${ }^{*} p<0.05$. 


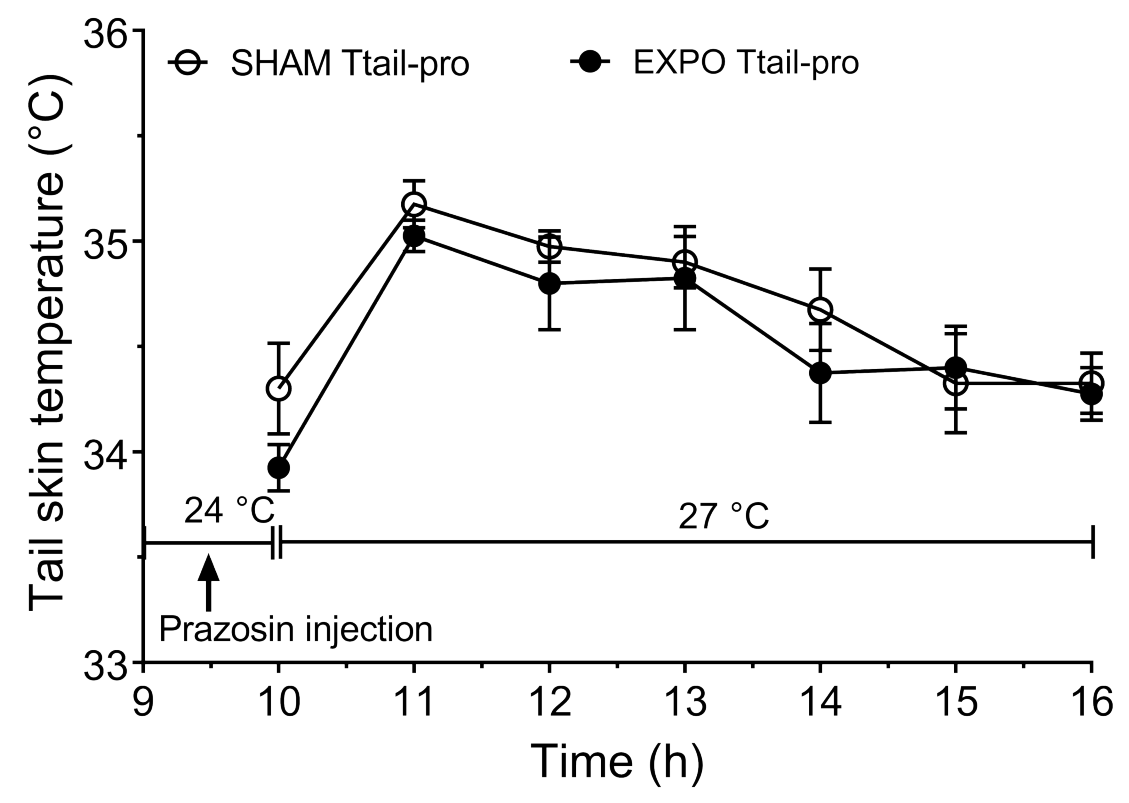

Figure 2. Tail skin temperature after prazosin injection at the ambient temperature of $27^{\circ} \mathrm{C}$. Each point is the average of 4 temperature values from 4 rats. Values are shown as means \pm SEM. 
a
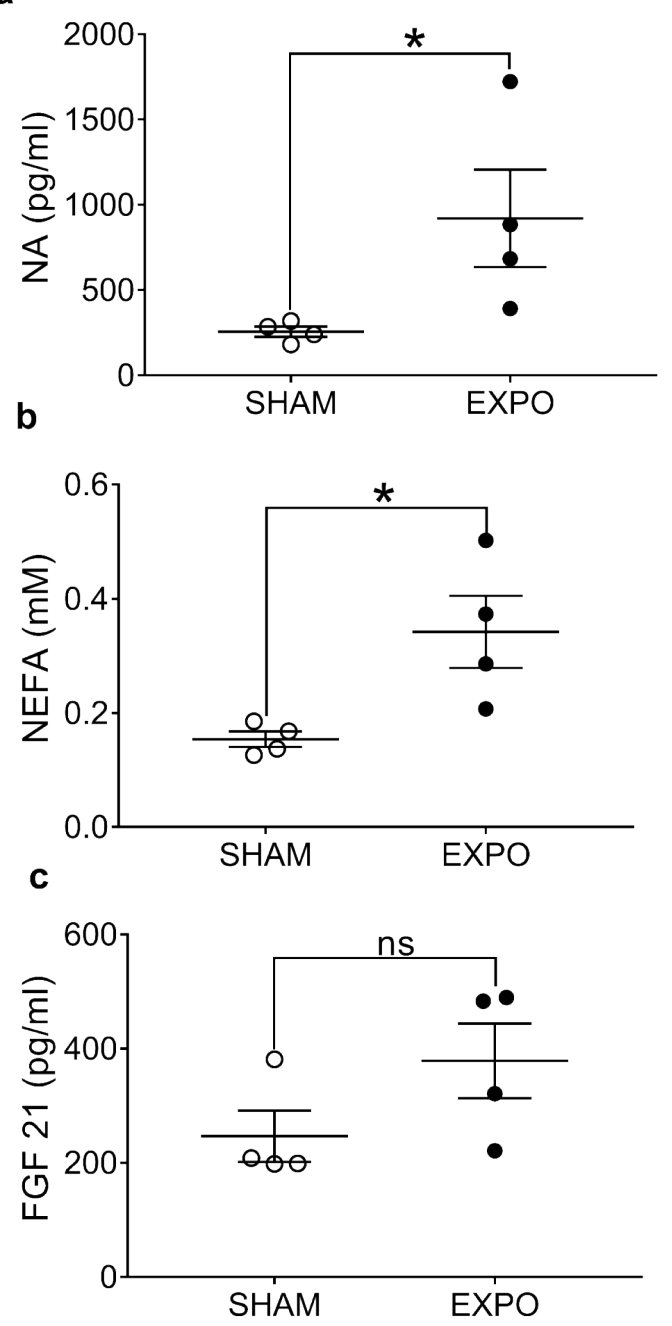

Figure 3. Plasma concentrations of (a) NA, (b) NEFA and (c) FGF21 in the SHAM and EXPO groups. Data were analyzed by Mann-Whitney U-tests. Values are shown as means \pm SEM, $n=4 .{ }^{*} p<0.05$ 


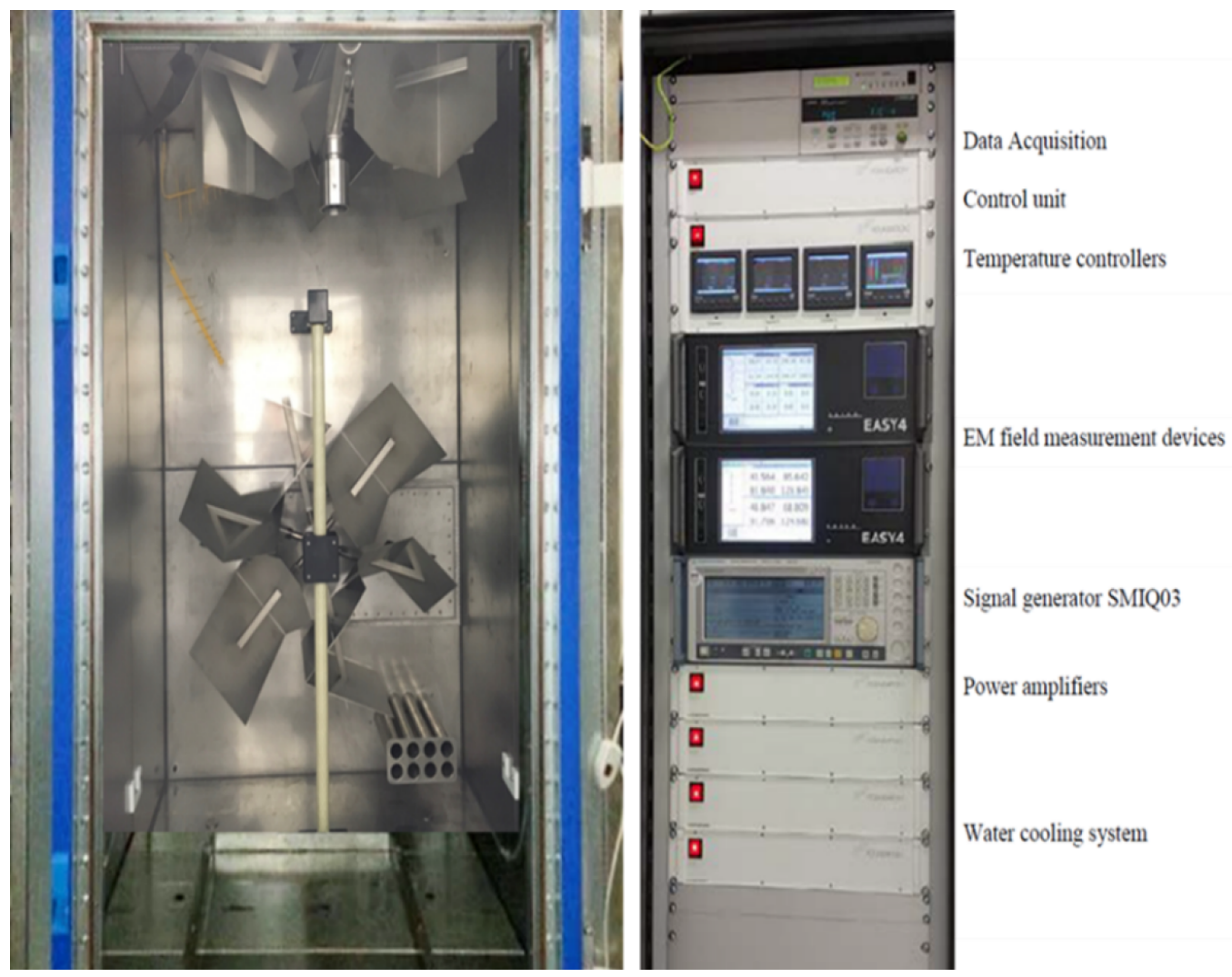

Figure S1. Exposure system. 


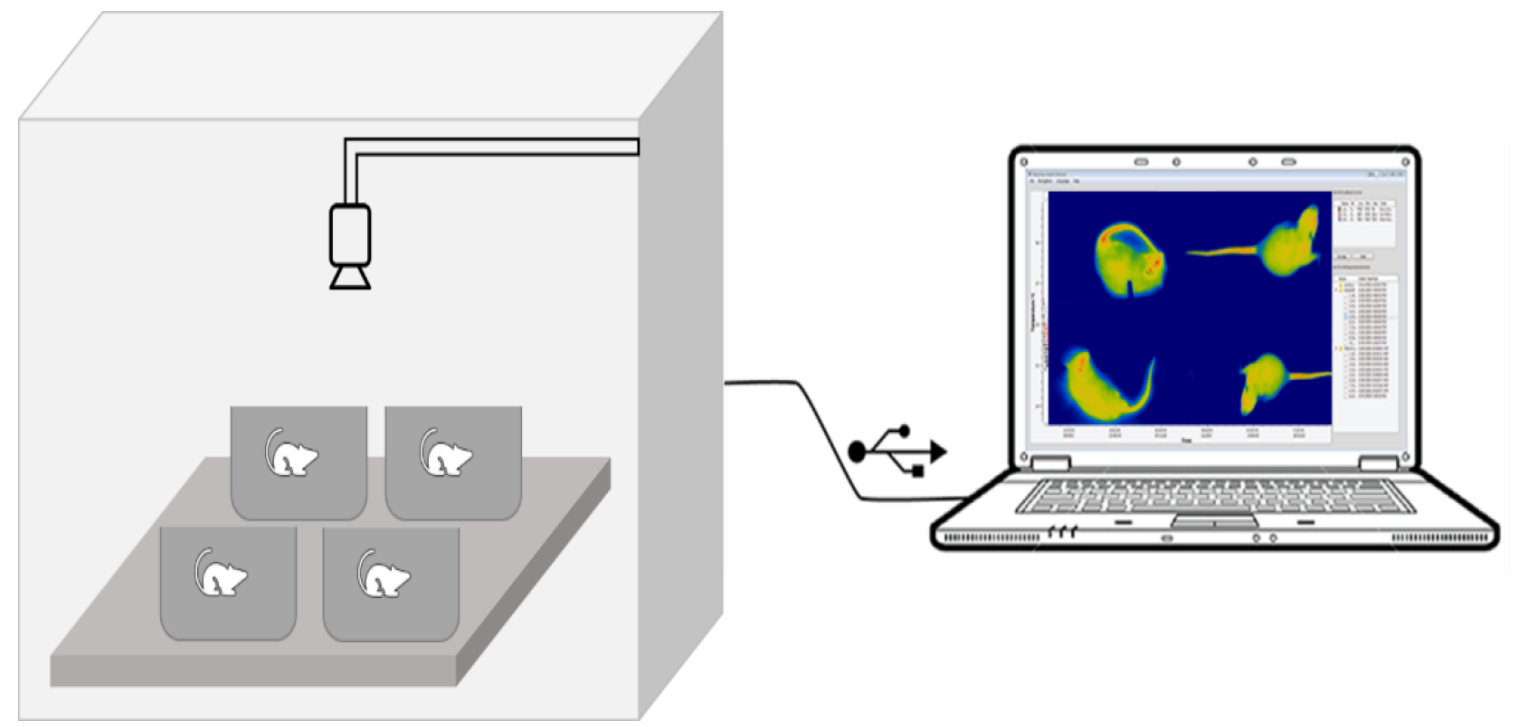

Figure S2. Experimental set-up during temperature monitoring. Rats were individually housed in plastic cages, 4 cages per reverberation chamber. Tail temperature was recorded by the IR camera. 

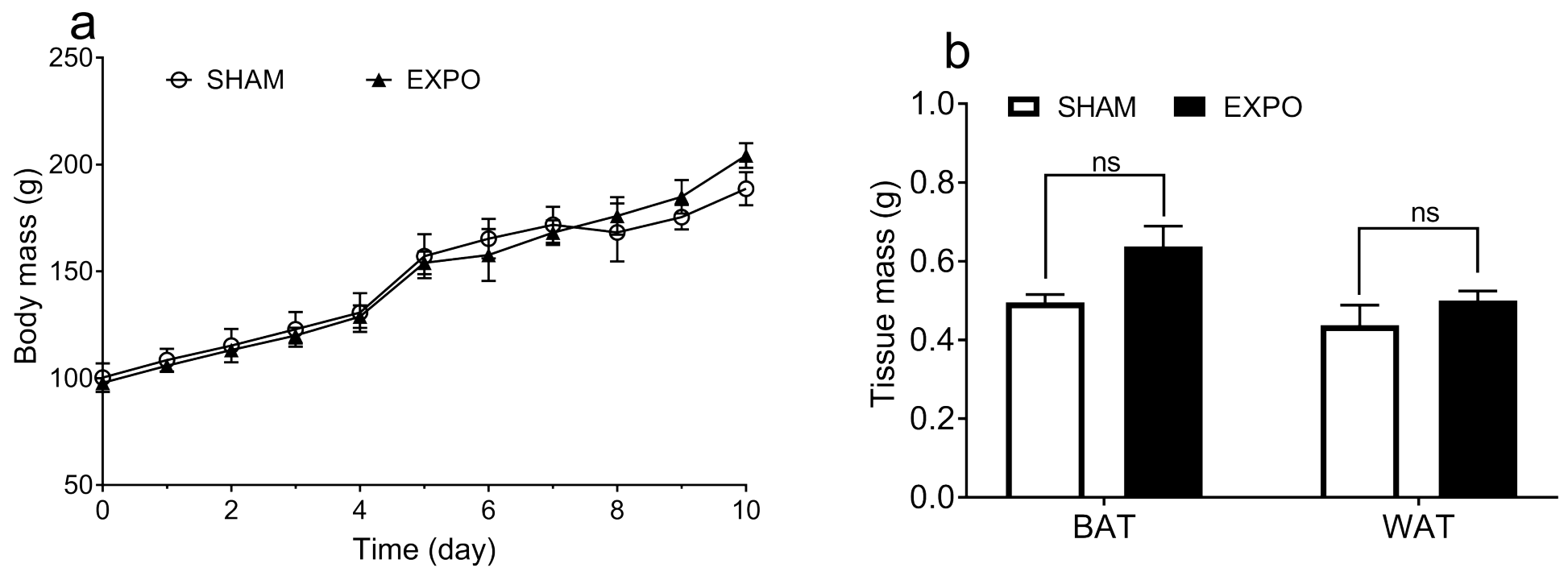

Figure S3. (a). Body weight over time (10 days of the experiment). (b) Weight of brown adipose tissue (BAT) and white adipose tissue (WAT), at the end of the experiment, ns: not significant. Values are shown as means \pm SEM. 


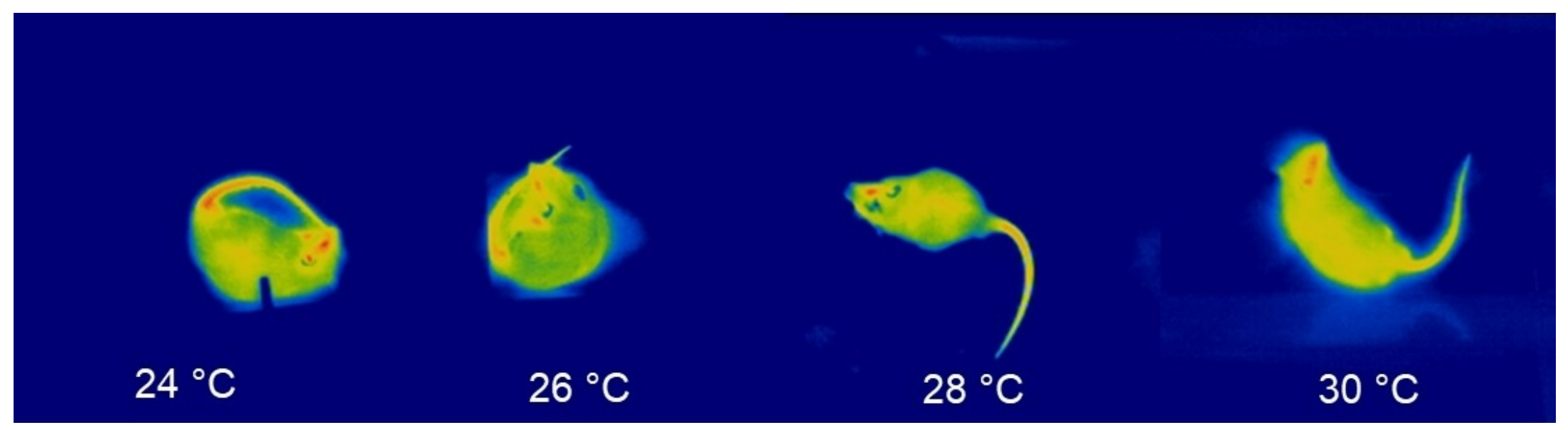

Figure S4. Position of the tail according to different ambient temperatures. 


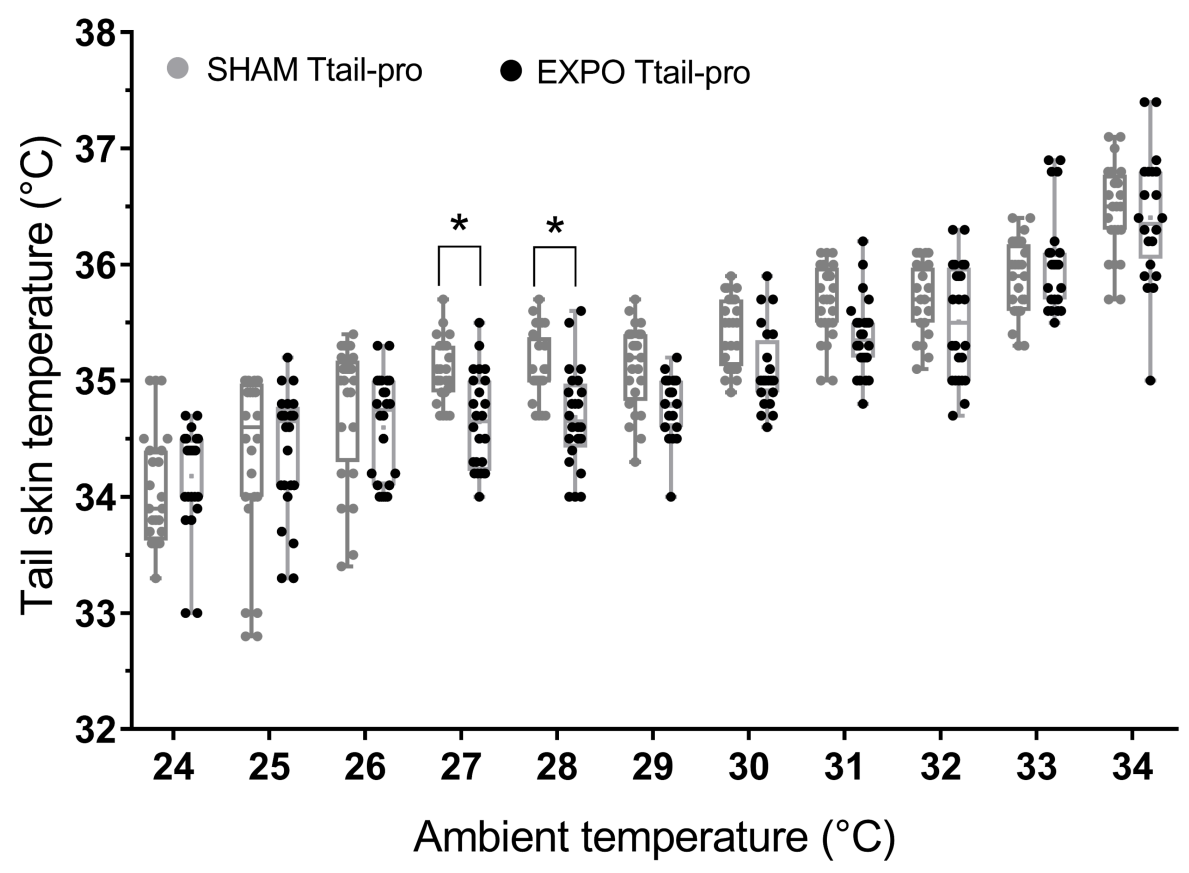

Figure S5. Tail skin temperature of the proximal parts of the tail at ambient temperatures ranging from 24 to 34 ${ }^{\circ} \mathrm{C}$. Each point represents a value tail temperature. 